九州大学学術情報リポジトリ

Kyushu University Institutional Repository

\title{
Molecular dynamics simulation of diffusion coefficients of naphthalene and 2-naphthol in supercritical carbon dioxide
}

\section{Iwai, Yoshio}

Department of Chemical Engineering, Faculty of Engineering, Kyushu University

Higashi, Hidenori

Department of Chemical Engineering, Faculty of Engineering, Kyushu University

Uchida, Hirohisa

Department of Chemical Engineering, Faculty of Engineering, Kyushu University

Arai, Yasuhiko

Department of Chemical Engineering, Faculty of Engineering, Kyushu University

http://hdl. handle. net/2324/12536

出版情報：Fluid Phase Equilibria. 127 (1-2), pp.251-261，1997-01-15. Elsevier バージョン:

権利関係: (C) 1997 Published by Elsevier Science B.V. 


\section{A paper submitted to Fluid Phase Equilibria (FEP-6021) revised manuscript}

\section{Molecular Dynamics Simulation of Diffusion Coefficients of Naphthalene and 2-Naphthol in Supercritical Carbon Dioxide}

Yoshio IWAI*, Hidenori HIGASHI, Hirohisa UCHIDA and Yasuhiko ARAI

Department of Chemical Engineering, Faculty of Engineering, Kyushu University, 6-10-1 Hakozaki,Higashi-ku, Fukuoka 812-81, Japan

Keywords : computer simulation, molecular dynamics, Lennard-Jones, diffusion coefficient, supercritical carbon dioxide, naphthalene, 2-naphthol

* Corresponding author 


\begin{abstract}
$N V T$ ensemble molecular dynamics simulation has been applied to calculate the diffusion coefficients of naphthalene and 2-naphthol in supercritical carbon dioxide in the pressure range from 8 to 40 MPa under infinite dilution condition. The Lennard-Jones (12-6) potential function was used as intermolecular potential. The calculation results showed good agreement with the experimental values, by using the intermolecular interaction parameters between unlike molecules which were determined by Monte Carlo simulation to give good representation for the solubilities of naphthalene and 2-naphthol in supercritical carbon dioxide.
\end{abstract}




\section{INTRODUCTION}

Supercritical fluid extraction has been given much attention recently as one of the new separation technologies in the chemical industry. One of the useful physical properties needed for the design of supercritical extractors and separators is the diffusion coefficients of high-boiling compounds under the supercritical conditions. However, measurements of the diffusion coefficients have been limited.

Recently, molecular dynamics (MD) simulation has been applied widely to calculate physical properties due to the rapid development of high speed computers. The Lennard-Jones potential is commonly adopted for intermolecular potential. Jolly and Bearman (1980), Schoen and Hoheisel (1984), Pas and Zwolinski (1991), and Heyes and Preston (1991) calculated the mutual diffusion coefficients in the Lennard-Jones mixtures of Ar-Kr, Kr-Xe, Xe-Ar, and Ar-methane by MD simulation. However, these systems consist of only small molecules and the Lorentz-Berthelot mixing rules were adopted for unlike pairs. Katagiri et al. (1993) calculated the diffusion coefficients of naphthalene in supercritical carbon dioxide by MD simulation with the Lennard-Jones potential. They also used the Lorentz-Berthelot mixing rules in spite of unsymmetrical system. It is interesting to check the applicability of the Lennard-Jones potential to unsymmetrical mixtures such as carbon dioxide - aromatic compound systems. In this work, the diffusion coefficients of naphthalene and 2-naphthol in supercritical carbon dioxide are calculated by MD simulation with the Lennard-Jones potential. It is shown that the calculated diffusion coefficients are in good agreement with the experimental data by using the parameters 
of perturbed Lorentz-Berthelot mixing rules which are determined to fit the solubility data by using Monte Carlo (MC) simulation.

\section{METHOD}

Potential function

For all particles in the present work, the Lennard-Jones (12-6) potential function was used

$$
\phi\left(r_{i j}\right)=4 \varepsilon_{i j}\left\{\left(\frac{\sigma_{i j}}{r_{i j}}\right)^{12}-\left(\frac{\sigma_{i j}}{r_{i j}}\right)^{6}\right\}
$$

where $\phi$ is the intermolecular potential, $\varepsilon$ is the energy parameter, $\sigma$ is the size parameter, $r$ is the molecular distance, and $i$ and $j$ denote the particles $i$ and $j$, respectively.

The interaction parameters between supercritical carbon dioxide 1 and aromatic compound 2 were given as

$$
\varepsilon_{12}=\left(1-k_{12}\right)\left(\varepsilon_{11} \times \varepsilon_{22}\right)^{1 / 2}
$$

and

$$
\sigma_{12}=\left(1-l_{12}\right)\left(\sigma_{11}+\sigma_{22}\right) / 2
$$


where $k_{12}$ and $l_{12}$ are the intermolecular interaction parameters between unlike molecules.

\section{Determination of potential parameters}

Aromatic compounds ; The corresponding state principle assures that all Lennard-Jones fluids for pure components obey the same reduced equation of state by using the reduced variables

$$
\rho^{*}=N \sigma^{3} / V, \quad T^{*}=k T / \varepsilon \text { and } P^{*}=\sigma^{3} P / \varepsilon
$$

where $\rho$ is the number density, $N$ is the number of particles, $V$ is the volume, $T$ is the absolute temperature, $P$ is the pressure, $k$ is the Boltzmann constant, and superscript $*$ means the reduced property. Nicolas et al. (1979) proposed the reduces critical constant values of $\rho_{\mathrm{c}} *, T_{\mathrm{C}} *$, and $P_{C} *$ at critical point as $0.35,1.35$, and 0.1418 , respectively. In this work, the parameters of aromatic compounds were calculated by using $T_{\mathrm{c}}$ and $P_{c}$. The values of critical constants of aromatic components and potential parameters adopted in this work are listed in Table 1.

Carbon dioxide ; In this work, the potential parameters of carbon dioxide were determined to represent the PVT relationship of pure carbon dioxide at $308.2 \mathrm{~K}$, because the $P V T$ relationship of supercritical carbon dioxide influences on the diffusion coefficients. NVT ensemble MD simulation using a leap-flog algorithm with the constraint method for constant temperature 
proposed by Brown and Clarke (1984) has applied to calculate the pressure of pure carbon dioxide. The pressures $P$ can be calculated by the following equation based on the virial theorem.

$$
P=\frac{N k T}{V}-\frac{1}{3 V}\left\langle\sum_{i}^{N} \sum_{j>i}^{N} \frac{\mathrm{d} \phi\left(r_{i j}\right)}{\mathrm{d} r_{i j}} r_{i j}\right\rangle
$$

A cubic cell with periodic boundary condition consisted of 256 particles of carbon dioxide was adopted and the half of side length of the cell was applied for the cut-off distance $r_{\text {cut }}$ between every pair particles. The influence of tail of the potential was estimated analytically, by assuming that the radial distribution functions were fixed to be unity for distances longer than $r_{\text {cut. }}$ The time step of the calculations was 10 fs. The number of equilibration steps was more than 3.0 $\times 10^{3}$ steps and that of the production steps was $2.0 \times 10^{5}$ steps. The pressures were calculated for every step. The pressure of the system was obtained by averaging these values. Fig.1 shows the calculated pressures of pure carbon dioxide by using the parameters fitted by the PVT relationship of pure carbon dioxide. The values of potential parameters adopted are listed in Table 1.

\section{Determination of intermolecular interaction parameters}

The intermolecular interaction parameters $k_{12}$ and $l_{12}$ were determined, to give good 
representation for the solubilities $y_{2}$ of aromatic compounds in supercritical carbon dioxide, by using NVT ensemble MC simulation. Details of the calculation procedure were reported previously (Iwai et al., 1995). These systems consist of 108 particles of carbon dioxide in a cubic cell with periodic boundary condition. The standard Metropolis importance sampling method (Metropolis et al., 1953) was used to obtain new configurations. Widom's test particle method (Widom, 1963) was adopted to calculate the residual chemical potentials of aromatic compounds in supercritical carbon dioxide. The chemical potentials for the aromatic compounds in pure solid phase were calculated by using the solid molar volume $v_{2} \mathrm{~S}$ and the saturated vapor pressures $P_{2}{ }^{\text {sat }}$ of the aromatic compounds. The values of $v_{2}{ }^{\mathrm{S}}$ and $P_{2}{ }^{\text {sat }}$ for naphthalene and 2-naphthol are listed in Table 2. After 2.0× $10^{5}$ configurations of carbon dioxide were generated to reach equilibrium condition, 50 test particles were tried to place at random locations for every 50 configurations of carbon dioxide. The length of calculations were $5.0 \times 10^{6} \sim 1.0 \times 10^{7}$ configurations of carbon dioxide. The values of interaction parameters determined are listed in Table 3. The calculated solubilities of naphthalene and 2-naphthol in supercritical carbon dioxide are shown in Fig.2. Introduction of the intermolecular interaction parameters $k_{12}$ and $l_{12}$ gave good agreement between the calculated solubilities and the experimental results.

\section{Calculation of diffusion coefficients}

In this work, $N V T$ ensemble MD simulation using leap-flog algorithm with constraint method for constant temperature proposed by Brown and Clarke (1984) have applied to calculate the 
diffusion coefficients of aromatic compounds in supercritical carbon dioxide. The time step of the calculations was $10 \mathrm{fs}$. The number of equilibration steps was more than $3.0 \times 10^{3}$ steps and that of the production steps was $1.0 \times 10^{6}$ steps. These systems consist of 256 particles. One of them is aromatic compound, and the other particles are carbon dioxide. So, the systems can be assumed to be at infinite dilution condition and the mutual diffusion coefficients were equal to the self diffusion coefficients of aromatic compound. The self diffusion coefficients of aromatic compound in supercritical carbon dioxide were calculated by the two methods shown below.

In the first method, the mean square displacements (MSD) of aromatic compound were used and the self diffusion coefficients of aromatic compound were calculated by the Einstein relation.

$$
D_{21}=\lim _{t \rightarrow \infty} \frac{1}{6 t}\left\langle\left[\boldsymbol{r}_{2}(t)-\boldsymbol{r}_{2}(0)\right]^{2}\right\rangle
$$

where $\boldsymbol{r}_{2}$ is the position of aromatic compound and $t$ is the time.

In the second method, the velocity auto-correlation functions (VAF) of aromatic compound were used and the self diffusion coefficients of aromatic compound were calculated by

$$
D_{21}=\frac{1}{3} \int_{0}^{\infty}\left\langle\boldsymbol{v}_{2}(t) \cdot \boldsymbol{v}_{2}(0)\right\rangle \mathrm{d} t
$$

where $\boldsymbol{v}_{2}$ is the velocity of aromatic compound. 
The examples of these functions were shown in Figs.3 and 4. The diffusion coefficients from MSD were calculated from the slopes shown in Fig.3 as an example in the time range from 20 to 50 ps. The diffusion coefficients from VAF were calculated by integrating the functions shown in Fig.4 as an example until the values of this function converged at zero (in the time range from 0 to 25 ps). It was checked that the diffusion coefficients calculated by these two methods gave almost the same values.

\section{RESULTS AND DISCUSSION}

The self diffusion coefficients of pure carbon dioxide can be calculated in the same manner by the aromatic compound particle is replaced by a carbon dioxide particle. Calculated self diffusion coefficients of pure carbon dioxide at 308.2 and $323.2 \mathrm{~K}$ are compared with experimental data as shown in Fig.5. It should be noted that the experimental data were self diffusion coefficients of ${ }^{12} \mathrm{CO}_{2}$ of ${ }^{12} \mathrm{CO}_{2-}{ }^{14} \mathrm{CO}_{2}$ system at $308.2 \mathrm{~K}$ and self diffusion coefficients of pure ${ }^{13} \mathrm{CO}_{2}$ system at $323.2 \mathrm{~K}$, and the calculation results were self diffusion coefficients of pure ${ }^{12} \mathrm{CO}_{2}$ system at $308.2 \mathrm{~K}$ and those of pure ${ }^{13} \mathrm{CO}_{2}$ system at $323.2 \mathrm{~K}$. The $95 \%$ confidence intervals are also represented by vertical lines. The $95 \%$ confidence intervals were calculated by using the sub-averages of diffusion coefficients for every $1.0 \times 10^{5}$ steps. The calculation results of self diffusion coefficients of pure carbon dioxide are in good agreement with the experimental data.

Calculated diffusion coefficients of naphthalene and 2-naphthol in supercritical carbon 
dioxide are shown in Figs.6 to 10. As shown in Figs.6 to 8, the calculation results of diffusion coefficients of naphthalene in supercritical carbon dioxide are in good agreement with the experimental data, by using the intermolecular interaction parameters $k_{12}$ and $l_{12}$ fitted to the solubility data. The diffusion coefficients of 2-naphthol in supercritical carbon dioxide calculated with and without the optimized intermolecular interaction parameters $k_{12}$ and $l_{12}$ are very similar, and are in good agreement with the experimental data as shown in Figs.9 and 10. The parameter $l_{12}$ has mainly influence on the diffusion coefficient and the value of $l_{12}$ determined by MC is nearly zero.

The shapes of naphthalene and 2-naphthol are very different than the Lennard-Jones spheres. They are somewhat planer. It should be noted that the molecular shapes are less important to good calculation results for diffusion coefficients for those systems.

\section{CONCLUSION}

In this work, MD simulation was performed to calculate the diffusion coefficients of naphthalene and 2-naphthol in supercritical carbon dioxide under the infinite dilution condition. By using the intermolecular interaction parameters $k_{12}$ and $l_{12}$ fitted to solubility data, the diffusion coefficients of naphthalene and 2-naphthol in supercritical carbon dioxide can be calculated by MD simulations with good agreement with the experimental data.

\section{ACKNOWLEDGMENTS}


The authors thank the Computer Center, Institute for Molecular Science, Okazaki National Research Institutes for the use of the NEC HSP and the Supercomputer Center, Institute for Solid State Physics, University of Tokyo for the use of the FACOM VPP500. H.Uchida is the Research Fellow of the Japan Society for the Promotion of Science (JSPS) for Young Scientists.

\section{LIST OF SYMBOLS}

\begin{tabular}{|c|c|}
\hline$D$ & diffusion coefficient, $\mathrm{m}^{2} \mathrm{~s}^{-1}$ \\
\hline$k$ & Boltzmann constant, J K ${ }^{-1}$ \\
\hline$k_{12}, l_{12}$ & binary interaction parameters between unlike molecules \\
\hline$N$ & number of particles in a cubic cell \\
\hline$P$ & pressure, $\mathrm{Pa}$ \\
\hline$r$ & position of a particle, $\mathrm{m}$ \\
\hline$r$ & molecular distance, $\mathrm{m}$ \\
\hline$r_{\text {cut }}$ & cut-off distance, $\mathrm{m}$ \\
\hline$t$ & time, $\mathrm{s}$ \\
\hline$T$ & absolute temperature, $\mathrm{K}$ \\
\hline $\boldsymbol{v}$ & velocity of a particle, $\mathrm{m} \mathrm{s}^{-1}$ \\
\hline$v$ & molar volume, $\mathrm{m}^{3} \mathrm{~mol}^{-1}$ \\
\hline$V$ & volume of a cubic cell, $\mathrm{m}^{3}$ \\
\hline
\end{tabular}


solubility (mole fraction)

\section{Greek letters}

$\varepsilon$

energy parameter, J

$\sigma$

size parameter, $\mathrm{m}$

$\rho$

number density, $\mathrm{m}^{-3}$

$\phi$

intermolecular potential, J

\section{Superscripts}

S

sat

*

\section{Subscripts}

C

$i, j$

1

2 solid phase

saturation condition

reduced value

critical property

particles $i$ and $j$

supercritical carbon dioxide

aromatic compound (naphthalene or 2-naphthol)

REFERENCES 
Angus, S., Armstrong, B. and de Reuck, K.M., 1976. Carbon Dioxide: International Thermodynamic Tables of the Fluid State-3, Pergamon Press, New York.

Brown, D. and Clarke, H.R., 1984. A comparison of constant energy, constant temperature and constant pressure ensembles in molecular dynamics simulations of atomic liquids. Mol. Phys., $51: 1243-1252$.

Debenedetti, P.G. and Reid, R.C., 1984. Diffusion and mass transfer in supercritical fluids. AIChE J., 32 : 2034-2046.

Etesse, P., Zega, J.A. and Kobayashi, R., 1992. High pressure nuclear magnetic resonance measurement of spin-lattice relaxation and self-diffusion in carbon dioxide. J. Chem. Phys., 97 : 2022-2029.

Fowler, L., Trump, W.N. and Vogler, C.E., 1968. Vapor pressure of naphthalene. New measurements between $40^{\circ} \mathrm{C}$ and $180^{\circ} \mathrm{C}$. J. Chem. Eng. Data, $13: 209-210$.

Heyes, D.M. and Preston, S.R., 1991. Equilibrium molecular dynamics computer simulations of the transport coefficients of Ar- $\mathrm{CH}_{4}$ mixtures. Molecular Simulation, 7 : 221-239.

Iomtev, M.B. and Tsekhanskaya, Y.V., 1964. Diffusion of naphthalene in compressed ethylene and carbon dioxide. Russ. J. Phys. Chem., 38 : 485-487.

Iwai, Y., Koga, Y., Hata, Y., Uchida, H. and Arai, Y., 1995. Monte Carlo simulation of solubilities of naphthalene in supercritical carbon dioxide. Fluid Phase Equilibria, 104 : 403-412.

Jolly, D.L. and Bearman, R.J., 1980. Molecular dynamics simulation of the mutual and self 
diffution coefficients in Lennard-Jones liquid mixtures. Mol. Phys., 41 : 137-147.

Katagiri, M., Matsumoto, S. and Tanaka, M., 1993. M.D. simulation of short-range order among molecules in supercritical dilute solution : solvation structure around solute molecule. In: M. Doyama, J. Kihara, M. Tanaka and R. Yamamoto (Eds.), Computer aided innovation of new materials II, Elsevier, Amsterdam, pp.279-282.

Knaff, G. and Schlünder, E.U., 1987. Diffusion coefficients of naphthalene and caffeine in supercritical carbon dioxide. Chem. Eng. Process., 21 : 101-105.

Lamb, D.M., Adamy, S.T., Woo, K.W. and Jonas, J., 1986. Transport and relaxation of naphthalene in supercritical fluids. J. Phys. Chem., 93 : 5002-5005.

Metropolis, N., Rosenbluth, A.W., Rosenbluth, M.N., Teller, A.H. and Teller, E., 1953. Equation of state calculations by fast computing machines. J. Chem. Phys., 21 : 1087-1093.

Nicolas, J.J., Gubbins, K.E., Streett, W.B. and Tildesley, D.J., 1979. Equation of state for the Lennard-Jones fluid. Mol. Phys., 37 : 1429-1454.

O’hern, Jr.H.A. and Martin, J.J., 1955. Diffusion in carbon dioxide at elevated pressures. Ind. Eng. Chem., 47 : 2081-2087.

Pas, M.F. and Zwolinski, B.J., 1991. Computation of the transport coeffisients of binary mixtures of argon-krypton, krypton-xenon, and argon-xenone by molecular dynamics. Mol. Phys., 73 : 483-494.

Perry, R.H., Green, D.W. and Maloney, J.O., (Eds.), 1984. Perry’s Chemical Engineering’s Handbook, 6th edn., McGraw-Hill, New York. 
Reid, B.C., Prausnitz, J.M. and Poling, B.E., 1987. The Properties of Gases and Liquids, 4th edn., McGraw-Hill, New York.

Schmitt, W.J. and Reid, R.C., 1986. Solubulity of monofunctional organic solids in chemically diverse supercritical fluids. J. Chem. Eng. Data, 31 : 204-212.

Schoen, M. and Hoheisel, C., 1984. The mutual diffusion coefficient $D_{12}$ in liquid model mixtures. A molecular dynamics study based on Lennard-Jones (12-6) potentials. II. Lorentz-Berthelot mixtures. Mol. Phys., 52 : 1029-1042.

Tan, C.-S. and Weng, J.-Y., 1987. Solubilities measurements of naphthol isomers in supercritical $\mathrm{CO}_{2}$ by a recycle technique. Fluid Phase Equilibria, $34:$ 37-47.

Tsekhanskaya, Y.V., Iomtev, M.B. and Mushkina, E.V., 1964. Solubilities of naphthalene in ethylene and carbon dioxide under pressure. Russ. J. Phys. Chem., 38 : 1173-1176.

Widom, B., 1963. Some topics in the theory of fluids. J. Chem. Phys., 39 : 2808-2812. 
Table 1 Critical constants and potential parameters

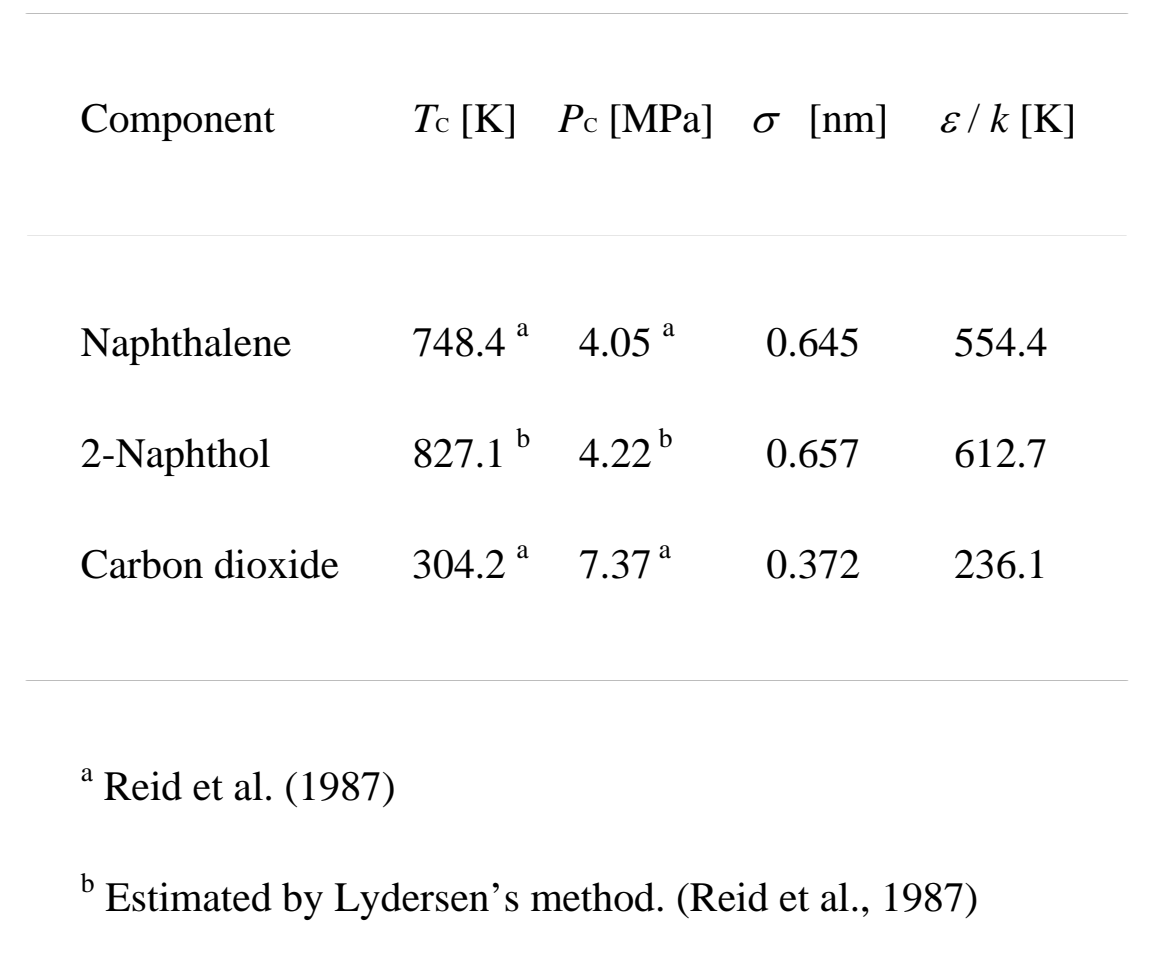


Table 2 Solid molar volumes and saturated vapor pressures of aromatic compounds

\begin{tabular}{lcccc}
\hline Aromatic & $V_{2}{ }^{\mathrm{S}} \times 10^{4}$ & \multicolumn{3}{c}{$P_{2}{ }^{\mathrm{sat}}[\mathrm{Pa}]$} \\
\cline { 3 - 4 } compounds $\quad\left[\mathrm{m}^{3} \mathrm{~mol}^{-1}\right]$ & $308.2 \mathrm{~K}$ & $318.2 \mathrm{~K}$ & $328.2 \mathrm{~K}$ \\
Naphthalene $\quad 1.119^{\mathrm{a}}$ & $29.17^{\mathrm{b}}$ & $71.27^{\mathrm{b}}$ & $159.0^{\mathrm{b}}$ \\
2-Naphthol & $1.18^{\mathrm{c}}$ & $0.0690^{\mathrm{c}}$ & $0.219^{\mathrm{c}}$ & \\
\hline & & & \\
\hline \\
\end{tabular}


Table 3 Intermolecular interaction parameters for $\mathrm{CO}_{2}$ (1)-aromatic compound(2)

\begin{tabular}{|c|c|c|c|c|}
\hline \multirow{2}{*}{$\begin{array}{l}\text { Aromatic } \\
\text { compounds }\end{array}$} & \multirow[t]{2}{*}{ Parameters } & \multicolumn{3}{|c|}{ Temperature [K] } \\
\hline & & 308.2 & 318.2 & 328.2 \\
\hline \multirow[t]{2}{*}{ Naphthalene } & $k_{12}$ & 0.05 & 0.05 & 0.03 \\
\hline & $l_{12}$ & 0.05 & 0.05 & 0.05 \\
\hline \multirow[t]{2}{*}{ 2-Naphthol } & $k_{12}$ & 0.05 & 0.05 & \\
\hline & $l_{12}$ & 0.01 & 0.01 & \\
\hline
\end{tabular}


Figure captions

Figure 1 PVT relationship of pure carbon dioxide : Equation of state, $\left(-\frac{}{-} 308.2 \mathrm{~K}\right.$; (-----) $318.2 \mathrm{~K}$; (-...-) $328.2 \mathrm{~K}$, Angus et al. (1976) ; MD calculations, ( $)$ 308.2 K ; $\square$ ) $318.2 \mathrm{~K}$; $(\triangle) 328.2 \mathrm{~K}$.

Figure 2 Solubilities of naphthalene and 2-naphthol in supercritical carbon dioxide : Experimental, (—— $308.2 \mathrm{~K}$; (-----) $318.2 \mathrm{~K}$; (-..--) $328.2 \mathrm{~K}$, naphthalene, Tsekhanskaya et al. (1964) ; (….......) $308.2 \mathrm{~K}$; (-.......) 318.2 K, 2-naphthol, Tan and Weng (1987) ; MC calculations with optimized parameters shown in Table 3, (○)

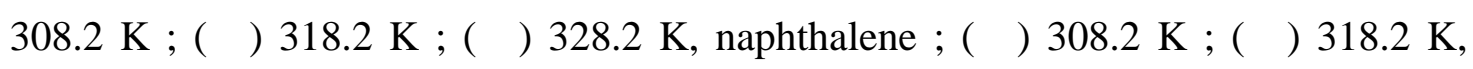
2-naphthol.

Figure 3 Mean square displacements (MSD) of naphthalene at $308.2 \mathrm{~K}$ and 10.6 MPa : calculated results ; (- $\longrightarrow$ ) slope of MSD from 20 to 50 ps.

Figure 4 Velocity auto-correlation functions (VAF) of naphthalene at $308.2 \mathrm{~K}$ and 10.6 MPa : $(-$ ) calculated results. 
Figure 5 Diffusion coefficients of carbon dioxide : $308.2 \mathrm{~K}$, Experimental, $(\bigcirc)$ O’hern and Martin(1955) for ${ }^{12} \mathrm{CO}_{2-}{ }^{14} \mathrm{CO}_{2}$ system ; MD calculations, (O) pure ${ }^{12} \mathrm{CO}_{2}$ system ; vertical lines represent fluctuations in calculated results ; $323.2 \mathrm{~K}$, Experimental, $(\triangle)$ Etesse et al.(1992) for pure ${ }^{13} \mathrm{CO}_{2}$ system ; MD calculations, ( $\left.\mathbf{\Delta}\right)$ pure ${ }^{13} \mathrm{CO}_{2}$ system ; vertical lines represent fluctuations in calculated results.

Figure 6 Diffusion coefficients of naphthalene at $308.2 \mathrm{~K}$ : Experimental, ( $\square$ ) Iomtev and Tsekhanskaya (1964) ; $\diamond)$ Knaff and Schlünder (1987) ; ( $\triangle)$ Lamb et al. (1986) ; MD calculations, $(\bigcirc) k_{12}=0.05, l_{12}=0.05 ;(\bigcirc) k_{12}=0, l_{12}=0$; vertical lines represent fluctuations in calculated results.

Figure 7 Diffusion coefficients of naphthalene at 318.2 K : Experimental, ( $\square$ ) Iomtev and Tsekhanskaya (1964) ; $\diamond)$ Knaff and Schlünder (1987) ; MD calculations, $k_{12}=0.05, l_{12}=0.05 ;(\bigcirc) k_{12}=0, l_{12}=0$; vertical lines represent fluctuations in calculated results.

Figure 8 Diffusion coefficients of naphthalene at 328.2 K : Experimental, ( $\square$ ) Iomtev and 
Tsekhanskaya (1964) ; $\diamond)$ Knaff and Schlünder (1987) ; $\triangle$ ) Lamb et al. (1986) ; MD calculations, $(\bigcirc) k_{12}=0.03, l_{12}=0.05 ;(\bigcirc) k_{12}=0, l_{12}=0$; vertical lines represent fluctuations in calculated results.

Figure 9 Diffusion coefficients of 2-naphthol at 308.2 K : Experimental, ( $\square$ ) Debenedetti and Reid (1984) ; MD calculations, (O) $k_{12}=0.05, l_{12}=0.01$; $(\bigcirc) k_{12}=0, l_{12}=0$; vertical lines represent fluctuations in calculated results.

Figure 10Diffusion coefficients of 2-naphthol at 318.2 K : Experimental, ( $\square$ ) Debenedetti and Reid (1984) ; MD calculations, $(\bigcirc) k_{12}=0.05, l_{12}=0.01$; $(\bigcirc) k_{12}=0, l_{12}=0$; vertical lines represent fluctuations in calculated results. 